\section{EL OTRO VIAJE DEL POETA OQUENDO DE AMAT

\author{
CARLOS MENESES
}

A unos 70 kilómetros de Madrid, en el cementerio de Navacerrada, hay una tumba que pertenece a un poeta peruano y en cuya lápida se lee: «Oquendo tan pálido/ tan triste/ tan débil/ que hasta el peso de una flor lo desvanecía», versos de otro poeta peruano, Enrique Peña Barrenechea. Muy de vez en cuando acude algún amante de las letras a visitar esa tumba, como quien reverencia a la propia poesía. Pocos saben la historia de este hombre que murió a los 30 años de edad en 1936. El había escrito en uno de los pocos poemas que forman su único libro Cinco metros de poemas, una verdadera sentencia: «Nadie debe vivir más de 30 años», y él cumplió su propio mandato, falleció cuando le faltaba un mes para añadir un año más a su dramática vida.

Tras su muerte y durante muchos años se hizo un gran silencio, y cuando se le volvió a recordar se tejieron las más raras conjeturas sobre su paso por Europa. Se decía que no existía su tumba, que había volado como consecuencia de los bombardeos franquistas. También que tras llegar a España procedente de París, había dado charlas sobre marxismo, leído sus poemas en alguna tribuna pública, y al estallar la guerra civil haber cogido el fusil e ido voluntariamente al frente de Aragón, donde habría sido víctima de las balas de las tropas antirepublicanas. No se sabía con exactitud su fecha de nacimiento, y tampoco cómo había sido su efímero paso por Europa.

Carlos Oquendo de Amat, nacido en $\mathrm{Pu}-$ no, Perú, en abril de 1905, hizo el viaje por mar desde el puerto del Callao hasta La Rochelle, Francia. Soñaba con conocer en París a los surrealistas franceses, con visitar la facultad de medicina donde había estudiado su padre, y con recorrer calles y plazas descritas en los muchos artículos que sobre la Ciudad Luz había leído. Pero sus ilusiones chocaron frontalmente con un monstruo llamado pobreza. El poeta creía que en todas partes del mundo encontraría una mano protectora que aplacara sus escasas apetencias. Pero no fue así, y los consejos de la diplomacia peruana en tierra francesa lo hicieron cambiar París por Madrid. «En España piensan como usted», parece que fue la frase con la que lo convencieron para que viajara a la capital española.

La realidad de la breve estancia de Oquendo en Madrid contrasta con todo lo imaginado por quienes conocían su poesía, algo de sus andanzas por el Perú, pero nada o casi nada de lo que hizo el poeta en Europa. Antes de arribar a puerto francés ya tuvo el primer percance. La policía norteamericana en la zona del Canal de Panamá, lo desembarcó por considerarlo un evadido de la justicia peruana. No era así, era un exiliado que tras cumplir cárcel por sus valientes y duras andanzas en el terreno de la política, había sido sentenciado a expulsión de su país por un gobierno reaccionario que no le perdonaba su militancia en un partido de izquierda.

A España Oquendo llegó con una pequeña maleta casi vacía, y tristemente, lo más llamativo de su persona era el mal estado en que se encontraban sus pulmones. Fue su mala salud la que le impidió realizar todo lo que hubiera querido hacer y se le atribuía. Prácticamente del tren que lo trajo de París a Madrid fue conducido e internado en el hospital San Carlos, hoy museo Reina Sofía. Y de ahí a insistencias suyas llevado al sanatorio de $\mathrm{Na}$ vacerrada, donde falleció a los tres meses de haber llegado a España. No hubo tiempo ni
Carlos Meneses:

(Lima 1930) Estudió Filosofía y Letras, especialidad Literatura, en la Universidad de San Marcos, de Lima, y Periodismo, en la Escuela de Periodismo, de Madrid. Ha publicado teatro, novela, cuento y ensayo, tanto en España como en el Perú y en México. Ha obtenido varios premios como el nacional de teatro del Perú en 1958; el Blasco Ibáñez, de Valencia, a su novela Edén Moderno, (2002) o el Peñíscola de cuentos por Lo que puede un pianista. Ha sido periodista en Lima, Santiago de Chile, Buenos Aires, Montevideo, Río de Janeiro, Madrid y Palma de Mallorca, ciudad en la que reside desde 1964 De sus biografías destacan las de Oquendo de Amat, Borges, J. Guillén, Miguel A. Asturias y Rafael Barrett. Ha sido crítico de libros entre los años 70 y 90 .

El otro viaje del poeta Oquendo de Amat

CARLOS MENESES 
fuerzas para conferencias, clamores contra las tropas que aplastaron a la República, y menos para que tomara su fusil y marchara hacia el frente. Pero toda esa fantasía se hubiera podido cumplir si el poeta no hubiese estado tan enfermo, y su transporte hacia el sanatorio de Navacerrada no hubiese sido tan dramático, como una indicación del destino de que su final no estaba nada lejano.

La llegada a la estación de Atocha de un joven de treinta años, portador de una maleta vieja y evidentemente de poco peso, lo que quedaba demostrado por la facilidad con que la llevaba ese hombre delgado que no evidenciaba fortaleza física ninguna, debió pasar desapercibida. Su mirada era triste pero transparentaba un hilo de luz optimista, como si estuviera convencido de conquistar Madrid. Al poco tiempo de su llegada y a pesar de ser un huraño de nacimiento ya habría congregado gente a su alrededor. Mucho habrían ayudado las cartas que traía desde que embarcó en el puerto del Callao, Perú, más que para poetas españoles, para gente del partido comunista o simpatizante con esa filiación. Se cumplían los últimos días del mes de diciembre de 1935, y en España bullía un clima de renovación que la derecha intentaba frenar desde tiempo atrás y que frenó violentamente con una guerra fraticida.

El poeta Oquendo desconocido en Europa, había tenido un paso desalentador por París. Sus ilusiones se comprimieron, nadie salió a su encuentro, no hubo poetas surrealistas que celebraran su llegada. Los días en la ciudad Luz fueron muy breves. Madrid era otra cosa. Alguien estaría esperándolo en Atocha, en efecto, así fue. Un escritor caribeño había sido avisado de la llegada del poeta nacido en Puno y acudió a darle la bienvenida. Fue este hombre de apellido Delgado quien le proporcionó alojamiento y lo introdujo en su círculo más político que literario. No obstante se preocupó porque también acudieran a conocer al peruano recientemente llegado poetas y narradores hispanos.

Por qué no podían presentarle a un Azorín ya entrado en años, a un Juan Ramón que aunque por momentos vitriólico podía sostener una agradable conversación con ese joven de semblante apacible y mirada triste. Y nada imposible sería que acudieran a conocerlo dos celebridades como Rafael Alberti y Federico García Lorca, que seguramente andaba por los alrededores de Madrid con su teatro ambulante «La Barraca» y toda la gente que lo solía acompañar. De esas conversas podría emerger una conferencia en el Ateneo, una lectura de sus poemas en alguna otra tribuna. Contactos con gente de partidos políticos, de izquierda naturalmente. Largas conversaciones en fábricas y centros de trabajo. Interminables momentos gratos de charlas en la Universidad contando por qué estaba fuera de su país, cuáles habían sido los motivos de su exilio.

Posiblemente Cansinos Asséns, curioso escritor y periodista, inspirador del ultraísmo en España, le buscaría impulsado por su instinto de procurador de celebridades. Tal vez, hasta habría leído algunos poemas de su único libro, en España no debería haber otro voraz lector como él, el único tan preocupado por enterarse de todo lo que ocurría en el mundo de las letras que habría saboreado los dieciocho poemas comprendidos en el libro «Cinco metros de poemas». Iría a su encuentro entusiasmado, con sus seis décadas a cuestas, a darle la mano y decirle que el poema «Madre» lo había conmovido, que el poema «Amberes» le había encantado y hasta se había sentido en esa ciudad mientras lo leía, pero habría añadido: «no son versos ultraístas, son creacionistas».

$\mathrm{Y}$ en el momento en que alguien invitaba un vaso de buen vino andaluz al poeta peruano, de un vino que hubiese encantado saborear a otro peruano excelente, César Vallejo, profesor de Oquendo en un colegio de Lima, un hombre se le acerca. Es un obrero al que el peruano trata con cortesía, y que le señala que es hora de acudir al Ateneo Obrero para que cuente su vida política. Sus momentos gratos y sus amarguras. Los días tras las rejas. Las violencias de la policía de un gobierno dictatorial. El encierro en una prisión del Canal de Panamá, la forma como escapó gracias a los amigos que su partido le había proporcionado a base de cartas para que faciliten su camino hasta llegar a Europa. Y Oquendo feliz, termina el vino y marcha hacia el lugar donde deberá hablar sobre sus experiencias de infatigable defensor de su pueblo, y hasta a lo mejor leer un poema, tal vez «Madre», que era uno de los que más quería.

Hablaría sobre su alejamiento de la poesía en 1929, coincidiendo con el año de la muerte de José Carlos Mariátegui, su maestro. De sus andanzas por las provincias andinas del Perú $y$ de su breve estancia en Bolivia, por motivos 
similares, concienciar al pueblo de la necesidad de liberarse de las formas anquilosadas con que eran tratados y aherrojados por sus respectivos gobiernos. Este Oquendo, con sus pulmones sanos, con su ansia de seguir conquistando mundo que apoye un cambio radical, hablaría incansablemente, sólo por una copa de vino, sólo por el abrazo de los compañeros, feliz con la retribución del aplauso, con los abrazos de los nuevos amigos españoles, con los avances de esas nuevas ideas que eran las suyas.

Otros amigos, los escritores que le ha presentado su amigo Delgado, el puertorriqueño que lo recibió en Atocha, lo llevan entrada la noche al café Colonial, al lugar donde hasta poco tiempo antes funcionaban varias peñas, la de teatro, la de tauromaquia, la de poetas, también en ese sitio habían estado y por muchas veces celebridades como Corpus Barga, el eximio articulista y excelente maestro. $\mathrm{Pu}-$ do haber sido en ese café donde Cansinos Asséns, el periodista que conocía perfectamente a todos los madrileños, fundara el ultraísmo en 1919 y todos sus discípulos concurrieran felices a escuchar su palabra, aunque luego eligieran el Pursiana para sus frenéticas fiestas de aquellos tiempos.

Y Carlos, el poeta delgado pero no desfalleciente como aquel otro que llegó a morir a España, preguntará airoso a quienes le acompañan, «¿por qué Cansinos me sitúa en las huestes del Creacionismo?». Pero no le habrá desagradado la clasificación que el gran tótem del ultraísmo había hecho de su obra. Siempre había soñado con Aragón, Breton, Reverdy. Con que los poetas de París salieran a su paso cuando él circulaba por las calles de la ciudad Luz, y lo abrazaran y se disputaran porque les recitara sus versos o porque les obsequiara Cinco metros de poemas, del que Carlos sólo tenía un ejemplar. Pero también se sentía orgulloso de que en Madrid, un señor que él escasamente conocía de nombre, hubiese leído varios de sus poemas antes de que él llegara a esa ciudad.

Y diría a algunos de los que seguían conversando con él, como una premonición. «Será difícil convencer a este pueblo de las bondades de las nuevas ideas que recorren Europa, hasta puede ser riesgoso pero hay que intentarlo cueste lo que cueste». Y simultáneamente, a los otros que hablan como cuchicheando sobre los poetas latinoamericanos: «En París hay un gran poeta peruano, se llama Vallejo». Alguno de los que acompañan a Oquendo le dice que sí, que sabía de ese Vallejo a través de Rafael Alberti y de Gerardo Diego pero que no había leído ni un solo verso de ese señor. Entonces Oquendo se refiere a Los heraldos negros y Trilce los dos libros de poemas que César Vallejo publicó en Lima antes de viajar a Europa. Pero agregará, lo busqué en París con insistencia pero no pude hallarlo.

Oquendo querrá conocer el acueducto que los poetas de los años veinte idealizaron. Y que lo lleven a la casa donde vivió Valle-Inclán, del que sabe se ha ido a su tierra gallega porque se halla muy enfermo, ignora en ese momento que el genial escritor de las barbas de chivo, como llamó Rubén Darío, estaba agonizando. Curioso por conocer la historia de España también pedirá visitar el sitio donde Goya inmortalizó a los fusilados por las huestes napoleónicas en 1808. Y seguirá demandando por lugares y personas, y recorriendo feliz Madrid. Convencido de que lo conocerá en su totalidad, y que luego hará lo mismo con Toledo y con Ávila. Y que querrá llegar hasta Andalucía, ¿y por qué no a Guipúzcoa, la tierra de su antepasado el célebre almirante Oquendo? De ninguna manera olvidará que en Barcelona había nacido otro gran antepasado suyo, el que fuera Virrey del Perú, Amat y Junyet.

Este hombre de los andes peruanos no es vigoroso, más bien da sensación de debilidad, pero no se cansa de inquirir por poetas, pintores, narradores, músicos, de los que ha tenido noticia en su país. Se percibe que ha sido un voraz lector. No sólo de revistas y diarios peruanos, también extranjeros, españoles y franceses. Y cuando menos se piensa hace referencia a dos revistas peruanas: Amauta dirigida por el célebre José Carlos Mariátegui, y en la que aparecieron varios de sus poemas, algunos de los cuales se integraron en su libro Cinco metros de poemas. Y también menciona otra revista desconocida para quienes los rodean y atienden, Boletín Titikaka. Explica que es una revista de la ciudad de Puno que está a las orillas del lago que le da el nombre, que no es un boletín de información local sino internacional, que recoge trabajos de escritores de fama mundial. Y ante la perplejidad de sus amigos va diciendo nombres hasta que pronuncia el de Jorge Luis Borges. Por supuesto no falta quien asegura haberlo conocido en España.

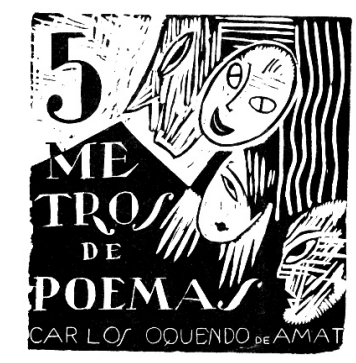

El otro viaje del poeta Oquendo de Amat

CARLOS MENESES 


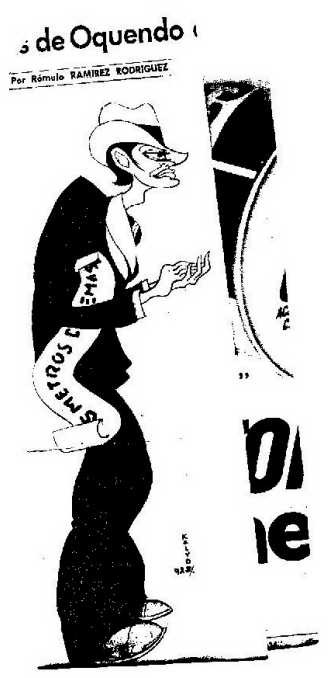

El otro viaje del poeta Oquendo de Amat

CARLOS MENESES
Oquendo sabe poco de Borges. Sólo conoce un pequeño cuento publicado en esa revista de su tierra, y haber leído un poema titulado «Rusia» que le encantó. No sabe que ese pequeño cuento que llevaba como título el muy simple de «Cuento policial», creció en extensión como había crecido el prestigio de su autor ante los ojos de los más severos lectores, y se convirtió en «Hombre de esquina rosada». Pero sí sabe que «Rusia» fue pergeñado durante la larga estancia de la familia Borges en Suiza, que se le hizo retoques más adelante, y que tras su publicación en Grecia, revista que nació modernista y derivó en ultraísta, así como también cambió de sede, de Sevilla a Madrid, ese poema desapareció de la circulación.

Le aconsejan que hable nuevamente con Cansinos, que es la clave para que le presente a la mucha gente que él desea conocer. En una mesa cercana del hermoso café está Pedro Garfias ante una copa de coñac. Le dicen que en ausencia de Cansinos puede ser la persona que le dé informaciones necesarias. Se acerca Garfias con la copa de coñac en la mano, asegura que conoció a Borges en Sevilla, que se volvieron a encontrar en Madrid, en pleno furor ultraísta. Afirma rotundamente haber leído el poema «Rusia», haber conocido a Vando Villar, director de la revista Grecia, saber que Borges había reunido cuentos y poemas para publicarlos en Madrid, pero que algo le hizo cambiar de decisión. Que todos los poemas con tinte soviético, que no eran muchos, habían desaparecido como por arte de magia. Y que los cuentos los había destruido. "Algún día aparecerán», lo consuela Oquendo sonriente.

En el hospital San Carlos está el otro Oquendo, el que llegó con los pulmones pulverizados a Madrid. El que clama desesperado que lo cambien de lugar, que no puede respirar porque está encerrado en un sitio inhóspito. Tanto insiste en el cambio que el agregado cultural de la embajada peruana, Porras Barrenechea, decide hacer las gestiones pertinentes para llevar al poeta a un sanatorio en la sierra del Guadarrama. El enfermo ignora lo muy avanzado del mal y la negativa de los médicos que lo atienden a ese cambio que consideran un grave riesgo. Oquendo está muy lejos de pensar que tras ese desplazamiento ya no habrá ningún otro más ni cercano ni lejano.
Este Oquendo posibilitado de buena salud, optimista y ansioso de conocer gente, ciudades, historia, no sólo pide que le cuenten la vida política y literaria de España, él también comunica lo suyo. Dice a quienes lo rodean que desciende del Almirante vasco, Oquendo, y que por vía materna entronca con el cazurro, impositivo y vivaz virrey Amat y Junyet, que dejara huellas de su temple militar en Chile, y que cumpliera una etapa de severo control en el Perú. Lo consideran noble ante ese linaje expuesto. Titubean antes de inquirir si él se siente socialmente en un alto nivel. El poeta sonríe, elimina temores. Sus antepasados sólo le han dejado los apellidos, su mente y su sensibilidad no proviene de genes tan antiguos. Cuenta sobre su padre, médico que estudió en París, diputado en el congreso de Lima, defensor de ideas avanzadas a favor del pueblo. A sus contertulios de ese momento les llega la calma tras las aclaraciones del poeta.

No obstante las exhaustivas explicaciones de Oquendo sobre la carrera política de su padre, no todos han quedado satisfechos, especialmente Pedro Garfias. Le interesa el relato sobre el comportamiento político del médico Oquendo, le ha llamado la atención que este joven que está sentado a su lado haya hecho referencia a sus antepasados hispanos, pero él prefiere oírlo hablar de su propia poesía. Entonces pregunta a boca de jarro: « ¿tu poesía es un sueño? ¿Has leído apasionadamente a Huidobro? ¿Qué te atrae del mar? ¿Por qué miras a la luna constantemente y quieres pintarla de colores? ¿Consideras que el cine ha influido en tus versos?». Ha lanzado las preguntas como si fuera una ametralladora. El poeta sonríe otra vez, parece pedir calma y disponerse a responder.

Dice con su voz casi atiplada y mirando directamente al autor de las preguntas: $\ll \mathrm{El}$ cine me gusta, me gusta mucho. Por eso lo he trasladado a mis versos. Algunos de mis poemas tienen ritmo cinematográfico, no todos. Yo diría que no ha habido una influencia sustancial sobre mí. Imagina un hermoso cofre, sobre él caen flores, lluvia, diamantes, truenos, lágrimas, risas, de todo. Esa caja es mi sensibilidad». Vuelve a sonreír como diciendo que ya ha respondido a todas las preguntas que le han hecho. Que no hay nada más que agregar. No obstante esa respuesta elegante de Oquendo, Garfias no cede. Quiere saber más. $\mathrm{El}$ interrogatorio se alarga. El poeta peruano 
escucha el cuestionario muy tranquilo, como si lo conociera de antemano.

Se produce una pausa. Carlos empieza a responder. «No me siento creacionista, tampoco surrealista. He leído a los franceses del XIX y del XX. Algo puede haber quedado en mí de ellos. Tampoco soy ultraísta, me interesaron mucho los poetas del Ultra, pero no tengo esa fuerza que lucen algunos» y vuelve a callar. Alguien, un poeta joven que más adelante se sabe que apellida Hernández y que mucho más tarde le dicen que se llama Miguel y ha venido a Madrid desde Orihuela, le formula una pregunta en voz baja, lentamente, como si temiera perturbarlo ¿La reunión de la poesía y la política, qué resultado te ha dado?. Oquendo vuelve a sonreír, luego queda serio, mueve la cabeza, está dispuesto a contestar con la misma seriedad que ha sido formulada la pregunta.

Las miradas de todos los que lo rodean se dirigen al poeta peruano. Aguardan con gran interés lo que va a decir el joven extranjero. «Cuando decidí tomar parte activa en la política y prácticamente cogí el fusil ya no hubo sitio para la pluma». Algunos quedan satisfechos con esa manifestación y no parecen dispuestos a exigir más. Hernández y Adriano del Valle muestran intranquilidad. No van a permanecer callados, es evidente que no les basta el breve argumento del hispanoamericano. Pregunta el de Orihuela, luego casi sin pausa interviene, Adriano. Miguel considera que la fusión entre ambas actividades es posible, y agrega: «Es casi algo natural. Imposible que un poeta separe una de la otra». Del Valle no es tan insistente en cuanto a esa amalgama, aunque la ha comprobado a través de algunos poetas de la ya prestigiosa generación del 27.

Oquendo se da tiempo para echar una mirada en redondo en la que caben todos quienes lo acompañan. Luego dice parsimonioso: «La poesía es flor, la política fuego. ¿cómo incendiar la flor, cómo sosegar el fragor de las balas». Ni a Garfias ni a Hernández han convencido las floridas palabras del poeta peruano. Pedro comenta que un poeta es un apasionado, y que la pasión del luchador es capaz de inflamar los versos más delicados. Cuando Miguel va a intervenir, el poeta andino que no se ha alterado inicia su respuesta: «La lucha por un ideal inflama el alma. Los poemas han de quedar intonsos de toda contaminación. Eso en lo que respecta a mí». Alguien aplaude. Es un hombre del- gado, no joven pero con talante propio de quien tiene la mitad de su edad, que debe ser medio siglo. Ha llegado en ese momento al café. Uno de los contertulios lo saluda, «hola, Corpus Barga, qué de tiempo que no te veía». El de nombre que resulta raro para el poeta de lejanas tierras se sienta procurando pasar inadvertido para el conjunto de amigos.

Adriano mira su reloj, calcula que se está haciendo tarde y debe marcharse, pero no quiere hacerlo sin antes plantear más que una pregunta un comentario. Para él es correcta la evitación de la sincronía que parece reclamar Hernández y lo manifiesta: «Lo que hace Oquendo es toda una hazaña. Preservar a la poesía de toda impureza». Don Corpus permanece callado. Garfias parece rendirse. Pero Miguel Hernández insiste. Para él se lucha tanto con las armas como con la escritura. «Eso es lo que he hecho, pero por separado. Cuando descubrí que con la lírica no se logra la justicia, le cerré la puerta a la poesía pero sin renunciar a ella». Más de uno le dio la razón, y casi todos se pusieron de pie a la vez, era hora de abandonar el elegante café. Del Valle le susurra al peruano que al día siguiente le entregará su libro La sombrilla japonesa, Oquendo agradece con sonrisa de encanto.

Ya andando hacia la puerta de salida Hernández señala que lo que le ha sorprendido del libro de Oquendo es la ausencia de toda protesta. «No hay malhumor» dice, «los poemas son muy bellos, pero parecen huir de la realidad». Garfias interviene sólo para indicar que la poesía del peruano tiene su contrapartida no en los propios versos sino en su decisión de romper toda torre de marfil y dirigirse hacia la lucha sin titubeos. «Oquendo ha escrito una poesía delicada, pulcra, e igualmente ha transitado el camino de la valentía, dar la cara, salir de la trinchera gritando ¡Viva la libertad! Y exponiéndose a las balas del enemigo». Todos parecen comulgar con esto último.

La noche madrileña está fría. Varios de los acompañantes del vate visitante ya se habían despedido. Corpus Barga era el único que no había abandonado el local. Otros tertulianos lo habrían acogido en su mesa. Uno de los pocos que acompañaba a Oquendo le recordó que al día siguiente tenía que leer poemas y dar una conferencia en el local del partido. Otro insinuaba que aún era pronto para retirarse a casa y que podrían beber una copa más en un bar próximo a la Gran Vía. El andino
El otro viaje del poeta Oquendo de Amat

CARLOS MENESES 
dio muestras de no haber desdeñado nunca la vida bohemia, aunque su serio paso por la política práctica y teórica le hubiera mermado muchas horas a la distracción.

Le hicieron saber que la España de esos momentos no se deslizaba por un sendero de rosas. Que aunque todos estimaban sus versos muchos querrían oír voces guerreras. Pronunciaron nombres de personajes que estaban perturbando el libre discurrir del país hacia nuevos caminos. Uno, el más osado, tal vez también el más dramático, habló con voz de trueno, quería que el amigo peruano supiera de los peligros que acechaban a diario. De la necesidad de estar preparados para cualquier grave contingencia. La continua percusión de ese trasladar amenazas que se oían por doquier a los oídos del poeta quebró su comportamiento sereno, haciendo emerger al guerrillero que había permanecido soñoliento bajo la capa del poeta.

Otros más abundaron en nuevos testimonios sobre la situación política. Parecería que le quisieran clavar lanzas al hispanoamericano para que prometiera poemas comprometidos.
Versos como explosiones. Granadas estallando en manos de los lectores. "No sé si sabré escribir esos poemas» respondió con humildad Oquendo. «Si la situación cambiara de signo, surgiera una grave amenaza para este país, sé coger el fusil y salir hacia el frente». Hubo un abrazo del más fervoroso de los contertulios. Todos empezaron a caminar hacia el bar que estaba cerca de la Gran Vía, donde tomarían supuestamente la última copa de la noche.

El otro Oquendo, tal vez en esos mismos momentos, agonizaba en el sanatorio de $\mathrm{Na}$ vacerrada. Cuando un enviado de la embajada peruana fue a visitarlo con la intención de cambiarlo de sitio, que era lo que el enfermo había pedido, sólo encontró su cadáver. Le entregaron la única pertenencia que había dejado: una vieja maleta. Enrique Chanyek, que así se llamaba el enviado del embajador peruano, era estudiante de medicina. Abrió la valija, lo único que encontró fue algo de ropa interior, y un ejemplar de El Capital de Karl Marx, que Oquendo estudió bajo la dirección de su maestro José Carlos Mariátegui.
El otro viaje del poeta Oquendo de Amat

CARLOS MENESES 